\title{
Ваго-ростові та амплітудні показники у дітей дошкільного віку із наслідками дисплазії кульшових суглобів
}

\section{Анна Руденко \\ Олександр Звіряка \\ Юлія Арєшина}

Сумський державний педагогічний університет імені А. С. Макаренка, Навчально-науковий інститут фозичної культури Суми, Україна

\begin{abstract}
Мета: вивчити вплив наслідків дисплазії кульшового суглобу на окремі показники фрізичного розвитку та амплітуди рухів у дітей дошкільного віку.

Матеріал і методи: дослідження проводилися на базі дошкільних навчальних закладів. Участь взяло 40 дітей 5-6 років із наслідками дисплазії кульшових суглобів (за результатами аналізу медичної документації). Методи дослідження: теоретичний аналіз та узагальнення літературних джерел; аналіз медичних карток; антропометрія (вимірювання маси тіла, зросту); гоніометрія; методи математичної статистики.

Результати: як у хлопців, так і у дівчат 5-6 років з наслідками дисплазії кульшових суглобів відмічені незначні відхилення у менший бік від середніх нормативних показників маси тіла. Також подібні відхилення зафіксовано за показниками зросту у дівчат 5-6 років. Показники амплітуди заинання на хворій кінцівці були достовірно меншими, ніж на здоровій,

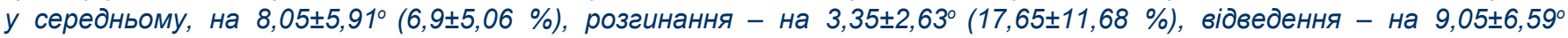

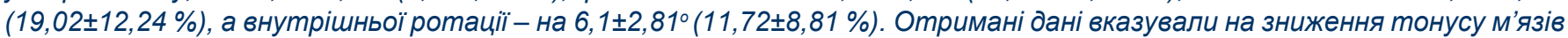
ураженої кінцівки, слабкість суглобово-зв'язкового апарату та зменшення об'єму рухів у кульшовому суглобі. Зміна показників амплітуди внутрішньої ротації хворої кінцівки відбулася на фонні вальгусної деформації колінних $i$ гомілковостопних суглобів.

Висновки: вплив наслідків дисплазії кульшового суглобу на показники фрізичного розвитку проявився у незначному відставанні від нормативних показників маси та зросту обстежених дітей. Порівняльний аналіз амплітуди рухів у кульшовому суглобі вказував на наявність статистично значимих відхилень між здоровою та хворою кінцівкою за такими напрямками руху, як зәинання, розгинання, відведення та внутрішня ротація.
\end{abstract}

Ключові слова: дисплазія кульшового суглобу, наслідки, ваго-ростові показники, амплітуда рухів, діти дошкільного віку.

\section{Вступ}

Дисплазія кульшового суглобу (ДКС) є важливою медико-соціальною проблемою сьогодення, що призводить до суттєвих змін та ускладнень в системі опорнорухового апарату (ОРА) дітей дошкільного віку. ДКС при несвоєчасному виявленні та невідповідному лікуванні, сприяє розвитку незворотних процесів у суглобовозв'язковому апараті, різкому погіршенню якості життя, негативно впливає на фрізичний розвиток та в подальшому $\epsilon$ причиною прояву різноманітних захворювань дитини [1; $3 ; 5 ; 8 ; 10 ; 12]$.

Однак, незважаючи на значні успіхи в діагностиці та лікуванні ДКС і низки запропонованих методів консервативного і оперативного лікування до теперішнього часу залишається недостатньо вивчена динаміка розвитку кульшового суглобу в залежності від методів лікування, а також не визначені критерії прогнозування перебігунаслідків цього захворювання $[4 ; 7 ; 9 ; 11]$. Тому виявлення негативних змін, які відбуваються у кульшовому суглобі та опорно-руховому апараті в цілому дітей дошкільного віку із наслідками ДКС $є$ актуальною проблемою фрізичної реабілітації.

Мета дослідження - вивчити вплив наслідків дисплазії кульшового суглобу на окремі показники фрізичного розвитку та амплітуди рухів у дітей дошкільного віку.

Завдання дослідження:

1. Проаналізувати та науково обґрунтувати сучасний стан проблеми ДКС та методи її дослідження.

2. Провести аналіз первинних ваго-ростових та амплітудних показників дітей дошкільного віку із наслідками ДКС.

\section{Матеріал і методидослідження}

Дослідження проводилися на базі Сумського спеціального дошкільного навчального закладу (ясла-садок) №20 «Посмішка» та Сумського дошкільного навчального закладу (ясла-садок) №33 «Маринка». У дослідженні взяли участь 40 дітей дошкільного віку (5-6 років) із наслідками дисплазії кульшових суглобів за результатами аналізу медичної документації. Батьки дітей, які приймали участь у дослідженні, були проінформовані з основними положеннями дослідження та підписали інформаційну згоду на участь у ньому. У даній групі дітей були присутні якхлопчики $(n=20)$, так і дівчатка $(n=20)$.

Для вирішення поставлених завдань використовувались наступні методи дослідження: теоретичний аналіз та узагальнення літературних джерел; аналіз медичних карток; антропометрія (вимірювання маси тіла, зросту); гоніометрія; методи математичної статистики.

Зв'язок роботи 3 науковими планами, темами. Робота виконана згідно з планом науково-дослідної роботи ННІФК Сумського державного педагогічного університету імені А. С. Макаренка МОН України на 2016-2021 pp. за темою «Теоретико-методологічні і організаційно- 


\section{СЛОБОЖАНСЬКИЙ НАУКОВО-СПОРТИВНИЙ ВІСНИК:}

\section{Матеріали XIX Міжнародної науково-практичної конференції «Фізична культура, спорт і здоров'я: стан, проблеми та перспективи»}

методичні проблеми здоров'я, фрізичної реабілітації та корекційної педагогіки» (номер державної реєстрації 0115U005933).

Аналіз останніх досліджень і публікацій. ДКС - найбільш поширене захворювання опорно-рухового апарату. Вітчизняні та закордонні ортопеди досягли значних успіхів у ранній діагностиці і своєчасному консервативному лікування ДКС (А. П. Джалилов, 2006, H. LaugePedersen et. al, 2006) [3; 14]. У дітей, яких пізно виявили ДКС прогресують зміни у кульшовому суглобі, відбуваються руйнування його елементів із виникнення комплексу адаптаційно-пристосувальних змін не тільки локальних, а й опорно-руховій системі у цілому [10; 11]. Такінегативні наслідки в свою чергу потребують диференціальної діагностики та відповідної фізреабілітаційної тактики (О. А. Малахов, 2003, В. І. Шевцов, 2006).

Отже, проблема ДКС є однією з найбільш складних і не до кінця вивчених у дитячій ортопедії. Більшість дослідників, описують рентгенологічні та ультразвукові методи дослідження ДКС, тим самим не приділяючи достатньої уваги інструментальним та антропометричним методам дослідження.

Наукові дослідження Б. Зеленецького (2010) свідчать про те, що дисплазія охоплює не тільки форму і взаєморозташування компонентів суглобу, але й ділянку кульшового суглобу, а саме кістки, хрящі, капсули, зв'язки та м'язи.

За твердженням науковців Є. Т. Скляренко (2005), В. О. Маркса (1978) ураження кульшового суглоба супроводжуються зниженням сили відвідних м'язів стегна та сідничних м'язів, що суттєво впливають на показники амплі- тудних рухів [3].

Численними науковими дослідженнями, доведено, що будь-які порушення у опорно-руховому апараті (кістковом'язовій системі та сполучній тканині) впливають нанормальний, повноцінний фрізичний розвиток дитини [2; 8; 9; $13]$.

\section{Результати дослідження}

Отже, дослідження було розпочато із вимірювання антропометричних показників: довжини тіла (зросту)та маси тіла дитини.

Антропометричні вимірювання є важливим показником оцінки фрізичного розвитку дітей [6] з патологією ОРА, а саме наслідками ДКС. Під фрізичним розвитком розуміють, комплекс морфо-функціональних властивостей організму, що характеризує процеси його росту та біологічного дозрівання. Тому, відхилення антропометричних показників від норми є підставою для проведення поглиблених досліджень та пошуку причин які спровокували негативні зміни у опорно-руховому апараті та кульшовому суглобі. Отримані в результаті дослідження дані наведені в таблиці 1 .

Як видно із таблиці, незначні відхилення у менший бік від середніх нормативних величин, запропонованих ВО3, спостерігалися за показниками маси тіла у всіх досліджених дітей, а також за показниками зросту у дівчат 5-6 років.

У ході аналізу медичних карток дітей 5-6 років із наслідками ДКС було, зокрема, встановлено наявність вальгусної дефрормації колінних і гомілковостопних суглобів.

Таблиця 1

Дані антропометричного обстеження дітей 5-6 років із наслідками ДКС

\begin{tabular}{|c|c|c|c|c|c|}
\hline \multirow{2}{*}{ Показник } & \multirow{2}{*}{$\begin{array}{l}\text { Вік, } \\
\text { роки }\end{array}$} & \multicolumn{2}{|c|}{ Група дітей } & \multicolumn{2}{|c|}{$\begin{array}{c}\text { Норма показників маси тіла та } \\
\text { зросту * }\end{array}$} \\
\hline & & $\begin{array}{l}\text { хлопці } \\
(n=20)\end{array}$ & $\begin{array}{l}\text { дівчата } \\
(\mathrm{n}=20)\end{array}$ & хлопці & дівчата \\
\hline \multirow[b]{2}{*}{ Маса тіла, кг } & 5 & $17,75 \pm 1,07$ & $18,1 \pm 1,11$ & 18,3 & 18,2 \\
\hline & 6 & $20,1 \pm 1,69$ & $19,75 \pm 1,07$ & 20,5 & 20,2 \\
\hline \multirow{2}{*}{ Зріст, см } & 5 & $114,1 \pm 1,45$ & $108,75 \pm 2,69$ & 110 & 109,4 \\
\hline & 6 & $117,35 \pm 1,86$ & $114,55 \pm 1,8$ & 116 & 115,1 \\
\hline
\end{tabular}

Примітка: * - за даними Всесвітньої організації охорони здоров'я (2007).

Таблиця 2

Показники амплітуди рухів у кульшовому суглобі дітей

\begin{tabular}{|c|c|c|c|c|c|}
\hline \multirow{3}{*}{$\begin{array}{c}\text { Напрям руху, } \\
\text { град. }\end{array}$} & \multirow{3}{*}{$\begin{array}{l}\text { Вік, } \\
\text { роки }\end{array}$} & \multicolumn{4}{|c|}{ Група дітей } \\
\hline & & \multicolumn{2}{|c|}{$\begin{array}{c}\text { дівчата } \\
(\mathrm{n}=20)\end{array}$} & \multicolumn{2}{|c|}{$\begin{array}{l}\text { хлопці } \\
(n=20)\end{array}$} \\
\hline & & здорова кінцівка & хвора кінцівка & здорова кінцівка & хвора кінцівка \\
\hline \multirow{2}{*}{ Згинання } & 5 & $117,75 \pm 7,25$ & $110,4 \pm 10,67^{*}$ & $115,5 \pm 5,28$ & $106,5 \pm 5,13$ \\
\hline & 6 & $121,85 \pm 8,26$ & $113 \pm 10,02^{*}$ & $117,5 \pm 8$ & $110,15 \pm 7,88^{*}$ \\
\hline \multirow[b]{2}{*}{ Розгинання } & 5 & $16,3 \pm 2,97$ & $12,2 \pm 3,34^{\text {***}}$ & $16,6 \pm 3,92$ & $12,7 \pm 4,03^{*}$ \\
\hline & 6 & $17,3 \pm 2,87$ & $14,55 \pm 3,45^{*}$ & $16,1 \pm 2,9$ & $13,45 \pm 3,2^{*}$ \\
\hline \multirow[b]{2}{*}{ Відведення } & 5 & $42,25 \pm 7,09$ & $32,25 \pm 7,66^{* * *}$ & $39,8 \pm 8,72$ & $32,6 \pm 9,01^{*}$ \\
\hline & 6 & $47,35 \pm 6,19$ & $39,05 \pm 11,94^{*}$ & $43,65 \pm 7,09$ & $32,9+6,40$ \\
\hline \multirow[b]{2}{*}{ Внутрішня ротація } & 5 & $40,85 \pm 5,13$ & $34,85 \pm 4,21^{\text {***}}$ & $39,9 \pm 9,68$ & $34 \pm 8,12^{*}$ \\
\hline & 6 & $41,9 \pm 10,09$ & $34,7 \pm 7,56^{*}$ & $40,6 \pm 7,44$ & $35,2 \pm 8,07^{*}$ \\
\hline \multirow{2}{*}{ Зовнішня ротація } & 5 & $34,65 \pm 8,33$ & $32,75 \pm 7,54$ & $32 \pm 6,09$ & $29,9 \pm 5,38$ \\
\hline & 6 & $36,45 \pm 9,05$ & $34,05 \pm 9,49$ & $39,05 \pm 6,5$ & $37,55 \pm 5,11$ \\
\hline
\end{tabular}

Примітки: * - відмінність від показників амплітуди руху здорової кінцівки статистично достовірна при р<0,05; ** відмінність від показників амплітуди рухуздорової кінцівки статистично достовірна при р<0, 005; *** - відмінність від показників амплітуди руху здорової кінцівки статистично достовірна при р<0,001. 


\section{СЛОБОЖАНСЬКИЙ НАУКОВО-СПОРТИВНИЙ ВІСНИК:}

\section{Матеріали XIX Міжнародної науково-практичної конференції «Фізична культура, спорт і здоров'я: стан, проблеми та перспективи»}

За даними В.Я. Віленського (2005) це може впливати на зміни показників амплітуди внутрішньої ротації ураженої кінцівки [3].

За допомогою гоніометрії були визначені показники амплітуди рухів у кульшових суглобах обох кінцівок (табл. 2).

Аналізуючи отримані результати, було встановлено, що різниця показників амплітуди згинання у дівчат 5 років між хворою кінцівкою (ХК) та здоровою кінцівкою (ЗК) складала $7,3 \pm 5,91^{\circ}(5,58 \pm 3,41 \%)$, у хлопців даного віку $-9 \pm 7,59^{\circ}$ $(7,6 \pm 6,25 \%) ;$ у дівчат 6 років $-8,85 \pm 6,02^{\circ}(7,07 \pm 4,07 \%)$, а у хлопців даного віку $-7,15 \pm 2,52^{\circ}(5,57 \pm 2,5 \%)$.

Різниця показників амплітуди розгинання у дівчат 5 років між ХК та $3 К$ складала $4,15 \pm 3,53^{\circ}(22,72 \pm 12,82 \%)$, у хлопців даного віку $-3,9 \pm 2,13^{\circ}(22,27 \pm 11,19 \%) ;$ у дівчат 6 років $-2,75 \pm 2,25^{\circ}(12,61 \pm 9,58 \%)$, а у хлопців даного віку $-2,65 \pm 1,91^{\circ}(13,04 \pm 7,98 \%)$

Різниця показників амплітуди відведення у дівчат 5 років між ХК та ЗК складала $10 \pm 8,71^{\circ}(22,03 \pm 11,15 \%)$, у хлопців даного віку $-7,2 \pm 5,83^{\circ}(16,09 \pm 12,21 \%)$; у дівчат 6 років $-8,3 \pm 3,2^{\circ}(16,39 \pm 7,97 \%)$, а у хлопців даного віку$10,75 \pm 6,55^{\circ}(21,55 \pm 14,97 \%)$.

Різниця показників амплітуди внутрішньої ротації у дівчат 5 років між ХК та ЗК складала $6 \pm 3,22^{\circ}(13,64 \pm 10,36 \%)$ у хлопців даного віку $-5,9 \pm 2,11^{\circ}(10,43 \pm 8,5 \%)$; у дівчат 6 років $-7,15 \pm 2,33^{\circ}(12,18 \pm 9,67 \%)$, а у хлопців даного віку $-5,35 \pm 3,06^{\circ}(10,63 \pm 5,16 \%)$.

Різниця показників амплітуди зовнішньої ротації у дівчат 5 років міжХК та ЗК складала $1,9 \pm 9,73^{\circ}(2,41 \pm 27,07 \%)$, у хлопців даного віку $-2,1 \pm 10,04^{\circ}(1,48 \pm 32,23 \%)$; у дівчат 6 років $-2,35 \pm 14,64^{\circ}(2,69 \pm 49,54 \%)$, а у хлопців даноговіку - $1,55 \pm 9,39^{\circ}(0,6 \pm 25,26 \%)$. За показниками зовнішньої ротації статистично значимих відмінностей між хворою та здоровою кінцівками виявлено не було.

За даними Т. І. Губарєва, Н. В. Мішаніної (2000), до подібних відхилень у амплітудних показниках може призводити ослаблення (зниження) тонусу сідничних м'язів та зменшення сили м'язів нижніх кінцівок, слабкість суглобово-зв'язкового апарату та деформації нижніх кінцівок, що часто спостерігаються у дітей із наслідками ДКС [4].

\section{Висновки /Дискусія}

1. Антропометричні вимірювання показали, що у дівчат та хлопців обох груп спостерігалися незначні відхилення від норми маси тіла, ймовірно спричинені порушенням нормального функціонування кульшового суглобу та опорно-рухової системи вцілому.

2. Порівняльний аналіз амплітуди рухів у кульшовому суглобі довів статистично значимі відхилення показників амплітуди між здоровою та хворою кінцівкою за такими напрямками руху, як згинання, розгинання, відведення та внутрішня ротація. Показники амплітуди згинання на хворій кінцівці були меншими, ніж на здоровій, у середньому, на $8,05 \pm 5,91^{\circ}(6,9 \pm 5,06 \%)$, розгинання - на $3,35 \pm 2,63^{\circ}$ $(17,65 \pm 11,68 \%)$, відведення - на 9,05 $\pm 6,59^{\circ}(19,02 \pm 12,24$ $\%)$, а внутрішньої ротації - на $6,1 \pm 2,81^{\circ}(11,72 \pm 8,81 \%)$. Зміна показників амплітуди внутрішньої ротації хворої кінцівки відбулася на фоні вальгусної деформації колінних і гомілковостопних суглобів.

Перспективи подальших досліджень полягають у вивченні показників тонусу сідничних м'язів та м'язів нижніх кінцівок у дітей 5-6 років із наслідками ДКС

Конфлікт інтересів. Автори заявляють, що немає конфлікту інтересів, який може сприйматися таким, що може нанести шкоду неупередженості статті. Джерела фінансування. Ця стаття не отримала фінансової підтримки від державної, громадської або комерційної організації.

\section{Список посилань}

\footnotetext{
1. Вільчковський, Е.С. (1998), Критерії оцінювання стану здоров'я, фізичного розвитку та рухової підготовленості дітей дошкільного віку, ІЗМН, Київ.

2. Вільчковський, Е.С., Курок, О.І. (2008), Теорія і методика фрізичного виховання дітей дошкільного віку, 2-ге вид., ВТД “Університетська книга", Суми

3. Виленский, В.Я. (2005), Диагностика и функциональное лечение врожденного вывиха бедра, Медицина, Москва.

4. Губарева, Т.И., Мишанина, Н.В. (2000), “Коррекция нарушений опорно-двигательного аппарата у детей в условиях дошкольного учреждения", Физическое воспитание в реабилитации детей дошкольного возраста с особенностями психофизического раз- вития, С. $80-82$.

5. Дудіна, О.О., Терещенко, А.В. (2014), “Ситуаційний аналіз стану здоров'я дитячого населення”, Вісник соціальної гігієни та організації охорони здоров'я України, № 2 (60), С. 49-57.

6. Калмикова, Ю.С. (2014), Методи дослідження у фізичній реабілітації: дослідження фрізичного розвитку: навчальний посібник для студентів вищих навчальних закладів фізичної культури і спорту напряму підготовки «Здоров'я людини», Харків.

7. Тарасова, Т.А. (2006), Контроль фризического состояния детей дошкольного возраста: метод. рекоменд. для руководителей и педагогов ДОУ, Сфера, Москва.

8. Яхно, Є. (2009), “Вікова динаміка фрізичного розвитку і фізичної підготовленості дітей на 5-6-му році життя", Спортивний Вісник Придніпров'я: наук.-практ. журнал, № 2-3, С. 41-43

9. Dezateux C. and Rosedahl K., (2007), "Developmental dysplasia of the hip", Lancet, Vol. 369 No. 95(72), pp. 1541-1552.

10. Harcke, H.T. (1999), "Developmental dysplasia of the hip: a spectrum of abnormality", Pediatrics, Vol. 103 No. 1, pp. 152.

11. Holroyd B. and Wedge J., (2009), "Developmental dysplasia of the hip", Orthop. Trauma, Vol. 23 No. 3, pp. 162-168

12. Loder R.T. and Skopelja R.T., (2011), "The Epidemiology and Demographics of Hip Dysplasia", ISRN Orthopedics, pp. 46.

13. Natale V. and Rajagopalan A., (2014), "World wide variation in human growth and the World Health Organization growth standards: a systematic review", BMJ Open, No. 4(1), pp. 8

14. Omeroglu H. and Koparal S., (2001), "The role of clinical examination and risk factors in the diagnosis of developmental dysplasia of the
} hip: a prospective study in 188 referred young infants", Arch. Orthop. Trauma Surg., Vol. 121, pp. 7-11.

Стаття надійшла до редакції: 11.11 .2019 р.

Опубліковано: 30.12.2019 p. 


\section{СЛОБОЖАНСЬКИЙ НАУКОВО-СПОРТИВНИЙ ВІСНИК:}

\section{Матеріали XIX Міжнародної науково-практичної конференції «Фізична культура, спорт і здоров'я: стан, проблеми та перспективи»}

Аннотация. Анна Руденко, Александр Звиряка, Юлия Арешина. Физическая терапия детей с отдельными дошкольного возраста с последствиями дисплазии тазобедренного сустава. Цель: изучить влияние последствий дисплазии тазобедренного сустава на отдельные показатели фьзического развития и амплитуды движений у детей дошкольного возраста. Материал и методы: исследования проводились на базе дошкольных учебных заведений. Участие приняли 40 детей 5-6 лет с последствиями дисплазии тазобедренных суставов (по результатам анализа медицинской документации). Методы исследования: теоретический анализ и обобщение литературных источников; анализ медицинских карт; антропометрия (измерение массы тела, роста); гониометрия; методы математической статистики. Результаты: как у мальчиков, так и у девочек 5-6 лет с последствиями дисплазии тазобедренных суставов отмечены незначительные отклонения в меньшую сторону от средних нормативных показателей массы тела. Также подобные отклонения зафиксированы по показателям роста у девочек 5-6 лет. Показатели амплитуды саи-

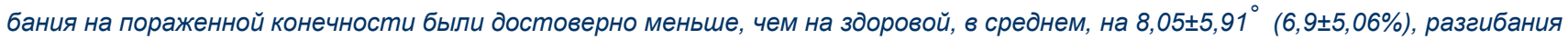
- на $3,35 \pm 2,63^{\circ}(17,65 \pm 11,68 \%)$, отведения - на 9,05 $6,59^{\circ}(19,02 \pm 12,24 \%)$, а внутренней ротации - на $6,1 \pm 2,81^{\circ}(11,72 \pm 8,81 \%)$. Полученные данные указывали на снижение тонуса мыши пораженной конечности, слабость суставно-связочного аппарата и уменьшение объема движений в тазобедренном суставе. Изменение показателей амплитуды внутренней ротации пораженной конечности произошло на фроне вальгусной деформации коленных и голеностопных суставов. Выводы: Влияние последствий дисплазии тазобедренного сустава на показатели фризического развития проявились в незначительном отставании от нормативных показателей массы и роста обследованных детей. Сравнительный анализ амплитуды движений в тазобедренном суставе указывал на наличие статистически значимых отклонений между здоровой и пораженной конечностью по таким направлениям движения, как сгибание, разгибание, отведение и внутренняя ротация.

Ключевые слова: дисплазия тазобедренного сустава, последствия, весо-ростовые показатели, амплитуда движений, дети дошкольного возраста.

Abstract. Anna Rudenko, Oleksandr Zviriaka, Yuliia Arieshyna. Weight and height rates and ranges of motion in preschoolers with consequences of hip joint dysplasia. Purpose: to study the impact of hip joint dysplasia on individual parameters of preschoolers' physical development and range of motion. Material and methods: The study was conducted at the nursery schools.

40 children of 5-6 years old with the effects of the hip joints dysplasia fixed in medical documentation took part in this study. Research methods: theoretical analysis and generalization of literary sources; medical cards analysis; anthropometry (weight, height measurements); goniometry; mathematical statistics methods. Results: Both boys and girls of 5-6 years old, who had the consequences of hip dysplasia, showed slight downward deviations from the average normative rates of body weight. The similar deviations were recorded in growth rates in girls of 5-6 years.

The values of the amplitude of flexion on the affected limb were significantly lower than on the healthy limb, on average, by $8.05 \pm 5.91$ (6.9 \pm 5.06 $\%)$, extension - by $3.35 \pm 2.63^{\circ}(17.65 \pm 11.68 \%)$, abduction - by $9.05 \pm 6.59^{\circ}(19.02 \pm 12.24 \%)$, and internal rotation - by $6.1 \pm 2.81^{\circ}(11.72 \pm 8.81 \%)$. These data indicated a decrease in muscle tone of the affected limb, weakness of the joints and ligamentous apparatus and a decrease in the range of motion in the hip joint. The decrease in the amplitude of the internal rotation of the affected limb took place on the background of valgus deformation of the knee and ankle joints. Conclusions: The effect of hip dysplasia on the indicators of physical development manifested in slight downward deviations from the normative indicators of bodyweight and growth of the examined children. A comparative analysis of the range of motion in the hip joint indicated the presence of statistically significant differences between the healthy and affected limbs in such directions as flexion, extension, abduction and internal rotation.

Keywords: hip joint dysplasia, consequences, weight and height rates, range of motion, preschoolers.

\section{References}

1. Vilchkovskiy, E.S. (1998), Kriteriyi ocinyuvannya stanu zdorov'ya, fizichnogo rozvitku ta ruhovoyi pidgotovlenosti ditej doshkilnogo viku [Criteria for assessing health status, physical development and motor fitness of preschool children], IZMN, Kyiv. (in Ukr.)

2. Vilchkovskiy, E.S. \& Kurok, O.I. (2008), Teoriya i metodika fizychnogo vykhovannya ditej doshkilnogo viku [Theory and methodology of physical education of preschool children], 2nd ed., VTD “University Book", Sumy. (in Ukr.)

3. Vilenskij, V.Ya. (2005), Diagnostika i funkcionalnoe lechenie vrozhdennogo vyviha bedra [Diagnosis and functional treatment of congenital hip dislocation], Medicine, Moscow. (in Russ.)

4. Gubareva, T.I. \& Mishanina, N.V. (2000), "Correction of disorders of the musculoskeletal system in children under the conditions of a preschool institution", Fizicheskoe vospitanie v reabilitacii detej doshkolnogo vozrasta s osobennostyami psihofizicheskogo razvitiya, pp. 8082 (in Russ.)

5. Dudina, O.O. \& Tereshchenko, A.V. (2014), "Situational analysis of the health of a child's population", Visnik socialnoyi gigiyeni ta organizaciyi ohoroni zdorov'ya Ukrayini, No. 2 (60), pp. 49-57. (in Ukr.)

6. Kalmikova, Yu.S. (2014), Metodi doslidzhennya u fizichnij reabilitaciyi: doslidzhennya fizichnogo rozvitku: navchalnij posibnik dlya studentiv vishih navchalnih zakladiv fizichnoyi kulturi i sportu napryamu pidgotovki "Zdorov'ya lyudini» [Methods for reaching physical education: reaching for physical education: an introductory compendium for students of basic primary mortgages in physical culture and sports, and direct training for "Healthy people"], Kharkiv. (in Ukr.)

7. Tarasova, T.A. (2006), Kontrol fizicheskogo sostoyaniya detej doshkolnogo vozrasta: metod. rekomend. dlya rukovoditelej i pedagogov DOU, [Monitoring the physical condition of preschool children: a method. recommended for managers and teachers of the DOU], Sfera, Moscow. (in Russ.)

8. Yahno, E. (2009), "Age dynamics of physical development and physical fitness of children in the 5-6th year of life", Sportivnij Visnik Pridniprov'ya: nauk.-prakt. zhurnal, No. 2-3, pp. 41-43. (in Ukr.)

9. Dezateux, C. \& Rosedahl, K. (2007), "Developmental dysplasia of the hip”, Lancet, Vol. 369 No. 95(72), pp. 1541-1552.

10. Harcke, H.T. (1999), "Developmental dysplasia of the hip: a spectrum of abnormality", Pediatrics, Vol. 103 No. 1, pp. 152

11. Holroyd, B. \& Wedge, J. (2009), "Developmental dysplasia of the hip", Orthop. Trauma, Vol. 23 No. 3, pp. $162-168$.

12. Loder, R.T. and Skopelja, R.T. (2011), "The Epidemiology and Demographics of Hip Dysplasia”, ISRN Orthopedics, pp. 46.

13. Natale, V. \& Rajagopalan, A. (2014), "World wide variation in human growth and the World Health Organization growth standards: a systematic review", BMJ Open, No. 4(1), pp. 8

14. Omeroglu, H. \& Koparal, S. (2001), "The role of clinical examination and risk factors in the diagnosis of developmental dysplasia of the hip: a prospective study in 188 referred young infants", Arch. Orthop. Trauma Surg., Vol. 121, pp. 7-11.

Received: 11.11.2019.

Published: 30.12 .2019 . 


\section{СЛОБОЖАНСЬКИЙ НАУКОВО-СПОРТИВНИЙ ВІСНИК:}

Матеріали XIX Міжнародної науково-практичної конференції «Фізична культура, спорт і здоров'я: стан, проблеми та перспективи»

\section{Відомості про авторів / Information about the Authors}

Руденко Анна Миколаївна: Сумський державний педагогічний університет імені А.С. Макаренка, Навчально-науковий інститут фрізичної культури: вул. Роменська 87, м. Суми, 40002, Україна.

Руденко Анна Николаевна: Сумской государственный педагогический университет имени А.С. Макаренка, Научноисследовательский институт фризической культуры: ул. Роменская 87, г. Сумы, 40002, Украина.

Anna Rudenko: Sumy State Pedagogical University named after A. S. Makarenko

Educational and Research Institute of Physical Culture: Romenskaya str. 87, Sumy, 40002, Ukraine.

ORCID.ORG/0000-0001-5428-6305

E-mail: rudenko_anna_87@ukr.net

Звіряка Олександр Миколайович: к. фріз. вих., доцент; Сумський державний педагогічний університет імені А.С. Макаренка, Навчально-науковий інститут фрізичної культури: вул. Роменська 87, м. Суми, 40002, Україна.

Звиряка Александр Николаевич: к. фриз. восп., доцент; Сумской государственный педагогический университет имени А.С. Макаренка, Научно-исследовательский институт физической культуры: ул. Роменская 87, г. Сумы, 40002, Украина.

Oleksandr Zviriaka: PhD (Physical Education and Sport), Associate Professor; Sumy State Pedagogical University named after

A. S. Makarenko, Educational and Research Institute of Physical Culture: Romenskaya str. 87, Sumy, 40002, Ukraine.

ORCID.ORG/0000-0001-8618-9665

E-mail: zvir-hunter@ukr.net

Арєшина Юлія Борисівна: к. фріз. вих.; Сумський державний педагогічний університет ім. А.С. Макаренка, Навчально-науковий інститут фрізичної культури: вул. Роменська, 87, м. Суми, 40002, Україна.

Арешина Юлия Борисовна: к. ффиз. восп.; Сумской государственный педагогический университет им. А.С. Макаренко, Учебнонаучный институт фризической культуры: ул. Роменская, 87, г. Суми, 40002, Украина.

Yuliia Arieshyna: PhD (Physical Education and Sport); Sumy State Pedagogical University named after A.S. Makarenko, Educational and Research Institute of Physical Culture: Romenska str., 87, Sumy, 40002, Ukraine.

ORCID.ORG/0000-0001-6375-465X

E-mail: julia.opheart@gmail.com 